Research Article

\title{
Construction Techniques and Quality Test and Evaluation of Lightweight Cellular Concrete Mixed with Fly Ash as Subgrade Material
}

\author{
Xin Liu $\left(\mathbb{D},{ }^{1,2,3}\right.$ Chengwei Ni, ${ }^{1,2,3}$ Hong Ji, ${ }^{4}$ Shuyan Tan, ${ }^{4}$ and Baoning Hong ${ }^{1,2,5}$ \\ ${ }^{1}$ Key Laboratory of Ministry of Education for Geomechanics and Embankment Engineering, Nanjing 210024, China \\ ${ }^{2}$ Jiangsu Research Center for Geotechnical Engineering Technology, Hohai University, Nanjing 210024, China \\ ${ }^{3}$ Institute of Tunnel and Underground Engineering, Hohai University, Nanjing 210024, China \\ ${ }^{4}$ Huaihe Water Conservancy Commission of the Ministry of Water Resources, Bengbu 233001, China \\ ${ }^{5}$ Geotechnical Research Institute, Hohai University, Nanjing 210024, China \\ Correspondence should be addressed to Xin Liu; liuxin100@hhu.edu.cn
}

Received 13 April 2019; Revised 11 May 2019; Accepted 11 June 2019; Published 24 June 2019

Academic Editor: Charles C. Sorrell

Copyright (c) 2019 Xin Liu et al. This is an open access article distributed under the Creative Commons Attribution License, which permits unrestricted use, distribution, and reproduction in any medium, provided the original work is properly cited.

\begin{abstract}
To improve the comprehension and utilization of lightweight cellular concrete mixed with fly ash (LCCF) and ensure project quality in subgrade construction engineering, the construction techniques and quality control measures of LCCF are studied in this paper. The corresponding research contents, based on a specific project case located in Guangdong Province, are as follows. Firstly, the construction technology process and technological measures are put forward, according to the site construction conditions and quality requirements. Secondly, the feasibility of indoor mixture ratio is further verified by measuring the fluidity, wet density, and strength on-site. Thirdly, the suitable pouring thickness of the single layer and reasonable interval time between layers are determined by the vertical delamination test and surface strength test. In this paper, the indoor mixture ratio of LCCF has been improved through tests such as single factor test and multifactor orthogonal test considering factors like fly ash, waterbinder ratio, and foam. Some highlights of this article are as follows: the preparation methods of lightweight concrete in laboratory and in situ are given. And two patented test devices are used for the strength test along with the depth and surface strength test, respectively. Besides, the practical engineering case is Lianjing Bridge, of which mileage pile number is $\mathrm{K} 80+679.679 \sim \mathrm{K} 80+760.113$, which is part of a highway in Zhaoqing City, Guangdong Province, China.
\end{abstract}

\section{Introduction}

Lightweight cellular concrete (LCC), as a very promising modern geotechnical material, due to its low density, adjustable strength, and self-reliance after curing, has more and more applications in civil engineering, such as in underground pipeline and cavity filling, especially in highway embankment filling [1-5]. A series of indoor and outdoor experimental research studies have been carried out to show that LCC is very suitable for civil engineering [6-8]. Most of the study focuses on compressive strength, stress-strain characteristics, and fiber improvement [9-11]. And Liu et al. [12] analyzed the durability using the method of analytic hierarchy process combined with a fuzzy comprehensive evaluation. Of course, new improved materials added for LCC remain to be found to accelerate the development of construction technology and ensure quality.

In recent years, fly ash has been gradually used as a new additive in civil engineering, ocean engineering, and other types of engineering. Some scholars have made many types of research on the performance of fly ash and drawn many useful conclusions [13-17]. In brief, the research usually focuses on using fly ash as the solely material for embankment filling, while research on the combination of LCC and fly ash for embankment filling is less. With the development of construction technology and the increasing use of fly ash, some scholars tried to mix fly ash with soil or cement, even lightweight aggregate. Santos et al. [18] considered that 
fly ash has the potential to be beneficially used in roadway constructions and described a study of the optimization of fly ash-soil mixture for highway embankment construction. Ibrahim et al. $[19,20]$ summarized that the addition of fly ash and concrete sludge as aggregate could help produce comparable concrete composites with lighter density. Luo et al. [21] carried out the study on mechanical properties of fly ash mixed with different quantities of clay. The research they have done not only reveals the properties of some materials mixed with fly ash but also promotes the engineering application of fly ash.

As can be seen in the previous studies, the research on the content of fly ash in lightweight concrete and engineering applications of the combination between LCC and fly ash for embankment filling are relatively less.

Therefore, some scholars start to study the characteristics and properties of LCC mixed with fly ash. Fang et al. [22] investigated the void structures of foamed concretes prepared from Portland cement, fly ash, steel slag, and foam agent. Chindaprasirt et al. [23] studied the shrinkage behavior of the structural foam lightweight concrete with fly ash. Some scholars have also studied the effects of different fly ash content on the properties of lightweight concrete. For instance, Shafigh et al. [24] analyzed the effect of cement replacement with type $\mathrm{F}$ fly ash at $0 \%, 10 \%, 30 \%$, and $50 \%$ on some engineering properties of an oil palm shell (OPS) highstrength lightweight concrete. The properties studied include workability, density, compressive strength, splitting tensile strength, flexural strength, water absorption, and drying shrinkage. Besides, some scholars also committed to develop optimal prefoamed lightweight foamed concrete and to achieve the desired density of lightweight concrete that is below $2400 \mathrm{~kg} / \mathrm{m}^{3}$ [25]. In addition, in view of operational performance and quality control measures, some scholars have also carried out related research. Liu et al. [26] analyzed the characteristics and distribution of fatigue life of LCC based on the method of accelerated stress tests. Also, they studied the wet density and unconfined compressive strength of LCCF and compared the construction techniques and critical points of quality control based on two abutments in China, behind which they are filled with LCCF and LCC [27]. The experiments they carried out also relied on microstructural methods like MIP and SEM test [28].

In general, it is apparent that the previous studies have mainly focused on the properties of LCCF. Also, there is a lack of surface strength test which will affect the interval between layers and strength test along depth which will affect the casting thickness of a single layer. Therefore, the main point of this work is to elaborate on the construction techniques and explore reasonable quality test and evaluation.

\section{Materials and Methods}

The engineering example of this study is Lianjing Bridge, of which mileage pile number is $\mathrm{K} 80+679.679 \sim \mathrm{K} 80+760.113$, which is part of a highway in Zhaoqing City, Guangdong Province, China. Due to the rich water system in the project area, the widespread soft subsoil, and its large burial depth, the lightweight concrete is considered as embankment filling material to reduce additional foundation load and settlement. The embankment behind the abutment is of a length of $17.7 \mathrm{~m}$, a height of $8 \mathrm{~m}$, a width of $12 \mathrm{~m}$, and the total pouring volume of $5000 \mathrm{~m}^{3}$.

\subsection{Construction Process and Technical Measures}

\subsubsection{Lightweight Concrete Production Process}

(1) Design of Mixture Ratio. In this research, the foam content is controlled at $700 \mathrm{~L} / \mathrm{m}^{3}$. The water/cement ratio is 0.58. And the content of fly ash, which is used as the equivalent replacement of cement, is adjusted to ensure the quality of lightweight concrete.

The service conditions of indoor mixture ratio (IMR) and engineering mixture ratio (EMR) of lightweight concrete are compared to verify the applicability of the indoor mixture ratio of LCCF. Combined with field construction conditions, the wet density and strength grade of the lightweight concrete are $7 \mathrm{kN} / \mathrm{m}^{3}$ and $1 \mathrm{MPa}$, respectively. According to the requirements of common LCC mixture ratio in embankment engineering and its technical indexes such as density and strength, when the wet density is no more than $7 \mathrm{kN} / \mathrm{m}^{3}$ and the strength is no less than $1 \mathrm{MPa}$ for 28 days, the common EMR is $1 \mathrm{~m}^{3}$ lightweight concrete $=400 \mathrm{~kg}$ of cement $+230 \mathrm{~kg}$ of water $+703 \mathrm{~L}$ of bubble. Similarly, the IMR of LCCF is $1 \mathrm{~m}^{3}$ lightweight concrete $=300 \mathrm{~kg}$ of cement $+100 \mathrm{~kg}$ of fly ash $+244 \mathrm{~kg}$ of water $+700 \mathrm{~L}$ of bubble.

(2) Raw Material Preparation. The hardening agent is ordinary Portland cement whose grade is 42.5 , which is provided by a cement factory in Zhaoqing City, Guangdong Province, China. Table 1 shows the physical properties of cement which meet the requirements of ASTM C311 [29]. The fly ash used in this research is collected from a fly ash cleaning company in Guangdong, China. According to Table 2, the $45 \mu \mathrm{m}$ sieve residues of fly ash are 8.6\%, which meet the fineness requirement of ASTM C618 [30]. The animal-plant protein compound foaming agent is adopted to produce LCCF in this research, which is a colorless liquid, and the $\mathrm{pH}$ is 7.5-9.0, and the construction water is just taken from the nearby pollution-free river.

(3) Construction Site Preparation Process of Lightweight Concrete. The preparation process of LCC is one of the critical factors affecting the initial damage. At present, the technology of preparing lightweight concrete is not mature in China. After several attempts, the improved preparation method of LCCF in this paper is as follows:

(i) Preparation of Cement Slurry. The cement and fly ash are weighed with an electronic scale according to the mixture ratio and mixed them evenly. Then, they are poured into the water as required and stirred for 3-5 minutes until no large particles are contained in the slurry. 
TABLe 1: Test items and results of cement.

\begin{tabular}{|c|c|c|c|c|c|c|c|}
\hline \multirow{2}{*}{$\begin{array}{l}\text { Specific surface area } \\
\left(\mathrm{m}^{2} / \mathrm{kg}\right)\end{array}$} & \multirow{2}{*}{$\begin{array}{c}80 \mu \mathrm{m} \text { sieve } \\
\text { allowance }(\%)\end{array}$} & \multicolumn{2}{|c|}{$\begin{array}{l}\text { Curing time } \\
\quad(\min )\end{array}$} & \multirow{2}{*}{$\begin{array}{l}\text { Stability } \\
(\mathrm{mm})\end{array}$} & \multirow{2}{*}{$\begin{array}{l}\text { Density } \\
\left(\mathrm{kg} / \mathrm{m}^{3}\right)\end{array}$} & \multicolumn{2}{|c|}{$\begin{array}{l}\text { Compressive } \\
\text { strength }(\mathrm{MPa})\end{array}$} \\
\hline & & Initial setting & Final setting & & & 3 days & 28 days \\
\hline 320 & 2.0 & 135 & 217 & 1.6 & 2650 & 26.5 & 46.8 \\
\hline
\end{tabular}

TABLE 2: Test items and results of fly ash.

\begin{tabular}{lcccc}
\hline $\begin{array}{l}45 \mathrm{~m} \text { sieve } \\
\text { residues (\%) }\end{array}$ & $\begin{array}{c}\text { Ratio of water } \\
\text { demand (\%) }\end{array}$ & $\begin{array}{c}\text { Water } \\
\text { content } \\
(\%)\end{array}$ & $\begin{array}{c}\text { Ignition } \\
\text { loss }(\%)\end{array}$ & $\begin{array}{c}\mathrm{SO}_{3} \\
(\%)\end{array}$ \\
\hline 8.6 & 93.5 & 0.95 & 4.3 & 2.6 \\
\hline
\end{tabular}

(ii) Preparation of Foam. LCCF is prepared by the preforming method; that is, the foam is prepared first and then manually measured and added into the slurry for mixing. The foaming agent is mixed with water to form a solution by volume ratio of 1 : 40 , and the foam is generated by a foaming machine.

(iii) Mix and Stir. A beaker is used to pour the foam into the cement slurry that has been mixed evenly before. The time for full mixing should be 5 minutes. When a layer of white foam cannot be seen floating on the slurry surface, it is considered that the slurry of LCCF has reached a uniform and stable state and can be poured.

(iv) Cast Model. In this experiment, $100 \mathrm{~mm} \times 100 \mathrm{~mm}$ $\times 100 \mathrm{~mm}$ cubic cast iron molds are used, as shown in Figure 1. Before pouring, a thin layer of mineral grease is applied on the inner surface of the mold, and then the LCCF slurry is poured into the mold. Because the slurry has the characteristics of selfleveling and self-compacting, the entire mold can be fully filled with the slurry with a gentle vibration.

(v) Maintenance. The models were covered with plastic wrap to prevent rapid evaporation of water, as shown in Figure 2. Since the early strength of LCCF is low, the pressing or stacking of heavy objects should be avoided within 24 hours. After curing for 24 hours under the constant temperature of $20( \pm 2)^{\circ}$ $\mathrm{C}$, the test blocks were demoulded and numbered and then the maintenance was continued till the design age, as shown in Figure 3. In the subsequent maintenance process, spray water in the maintenance room every 5 days to ensure sufficient humidity. The preparation flowchart of LCCF is shown in Figure 4.

According to the actual construction, the preparation of lightweight concrete is divided into three steps, as shown in Figure 5. Firstly, the cement slurry is made. Secondly, the foam is produced. The production of foam and cement slurry is carried out simultaneously, and the foaming agent is diluted at the dilution ratio $(1: 40)$ before foaming. Lastly, the lightweight concrete is made. The prepared cement slurry is transported to be mixed with

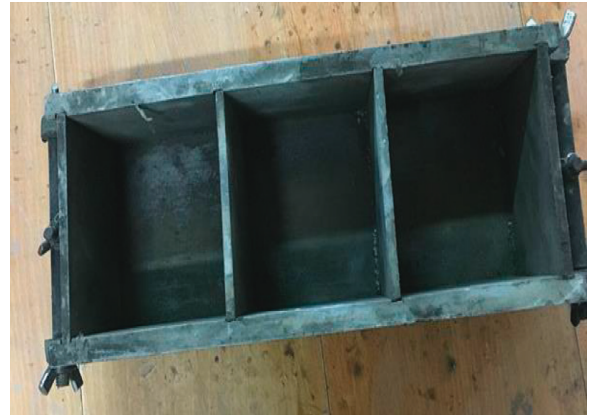

Figure 1: Cubic cast iron mold.

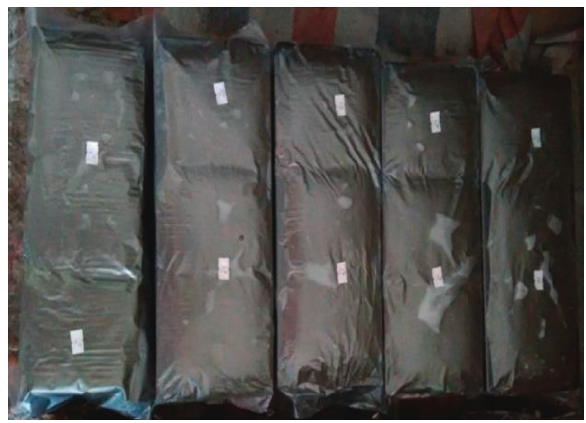

Figure 2: Test blocks.

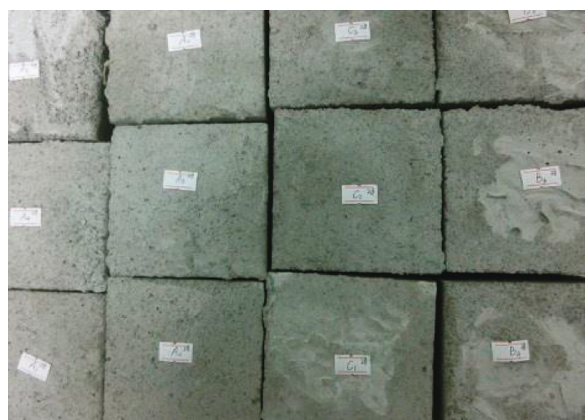

Figure 3: Test blocks in maintenance.

foam and sufficiently stirred to form a homogeneous slurry, which will be pumped at a fixed flow rate to the designated area of the pouring site. To ensure the quality of the lightweight concrete, the field also uses the electronic control system to monitor the construction parameters in real time and displays the flow rate of foaming agent, foaming liquid, compressed air, foam, cement slurry, and LCC through the touch screen or tablet computer. 


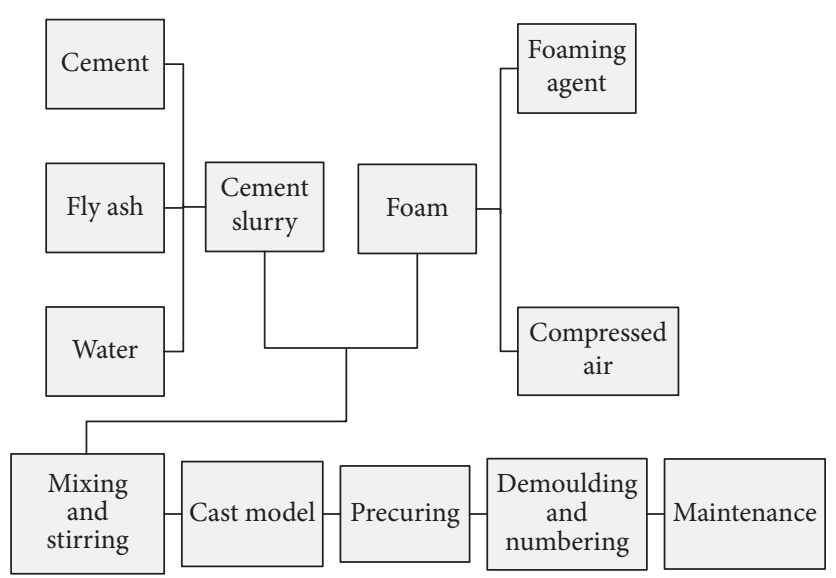

Figure 4: Preparation flowchart of LCCF.

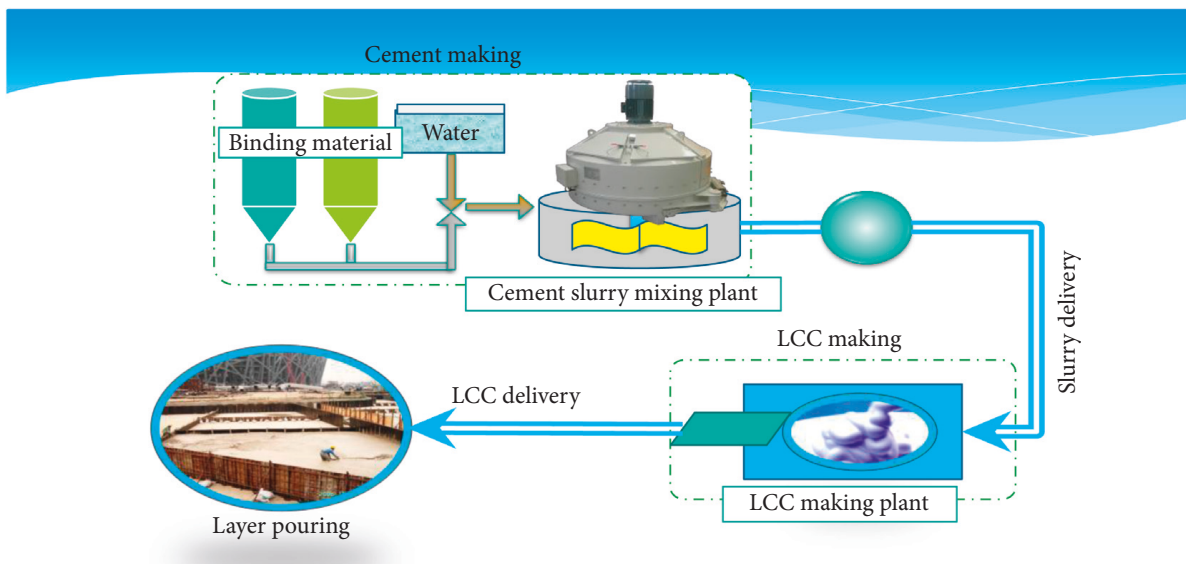

Figure 5: Process flowchart of preparation of lightweight concrete.

2.1.2. Casting Process. Due to large amount of lightweight concrete in this project, to ensure the construction quality and reduce the influence of hydration heat during mass pouring, the subgrade is divided and layered, and baffles are used to separate different blocks, as shown in Figure 6.

There are a large number of air bubbles in lightweight concrete. If the concrete tank truck or tipper truck is used for transportation, it will increase the digestion of air bubbles due to the influence of vibration in the transportation process and eventually reduce the air content, fluidity, and other technical indicators. However, if the lightweight concrete is transported by pipeline, the amount of bubble elimination will be minimal. Therefore, given the characteristics of lightweight concrete, a pipe is adopted for pumping, and the distance between the mixing station and the farthest pouring point is less than $500 \mathrm{~mm}$. The control points of the pouring process are as follows:

(i) Each pouring layer should be finished within the initial setting time of cement slurry and should not exceed 3 hours. The interval between the preparation of cement slurry and lightweight concrete should not exceed 3 hours. Fresh, lightweight concrete should not be suspended in the pumping equipment for more than 1 hour.

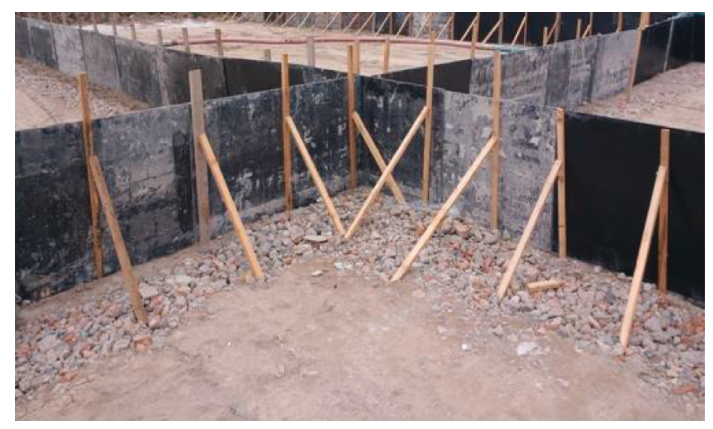

FIgURe 6: Partition panel.

(ii) According to the results of the test section of this project, it is considered that the thickness of a single layer of lightweight concrete should not exceed $0.5 \mathrm{~m}$. In terms of labor-saving and construction period, each pouring thickness of this project is set as $0.5 \mathrm{~m}$, and the height of each step is $2 \mathrm{~m}$. Therefore, each step is divided into four layers, and a single layer is poured at one time.

(iii) The pouring of the upper layer is carried out after the final set of the lower layer. It is subject to the fact that there is no depression or visible footprints 
when people walk on the filling body of the lower layer. The interval time between layers varies slightly with different seasons and different proportions. In this project, the interval of interlayer pouring shall be at least 12 hours and 9 hours, respectively, after the last setting in terms of IMR and EMR when the temperature is high, and at least 24 hours and 18 hours, respectively, when the temperature is low.

(iv) A pouring pipe is used along the long axis of the casting area from the middle to both ends. In the pouring process, the moving disturbance in the pouring layer should be minimized. When there is a significant difference in the casting layer, it is advisable to start from a lower position.

(v) The outlet end of the pumping pipe should always remain close to the casting surface. No matter is moving the pumping pipe, leveling the surface, or flushing the excess foam in the pouring area, the operator must ensure that the height of the port and the current lightweight concrete flow surface is less than $1 \mathrm{~m}$.

(vi) After finishing the subgrade pouring work, it must be covered with plastic film or geotextile to ensure sufficient humidity, and the wet curing time should not be less than seven days. When the lightweight concrete has not fully solidified, it is strictly prohibited to walk on it.

2.1.3. Auxiliary Construction Technology. According to the characteristics of this project, it is suggested that the auxiliary measures such as high-density polyethylene (HDPE) impervious geomembrane, construction joints, protection panels, and steel-plastic geogrids be appropriately adopted to ensure the elegance, safety, and service life of lightweight concrete embankment.

(1) HDPE Impervious Geomembrane. HDPE impervious geomembrane should be laid at the top and bottom of the lightweight concrete filling body. The top geomembrane is arranged after the curing, and it should wrap the surrounding cement $0.5 \mathrm{~m}$ down from the top around the protective wall. The geomembrane adopts double weld hot melt welding technology and is sealed with a batten.

(2) Steel-Plastic Geogrids. The steel-plastic geogrids on the top layer are laid below the impervious geomembrane and arranged laterally along the embankment. The overlap length in the direction of stress is higher than $30 \mathrm{~cm}$, while the overlap length in the direction of nonstress is greater than $10 \mathrm{~cm}$. The steel-plastic geogrids are fixed with $\mathrm{u}$-shaped nails with spacing $2 \mathrm{~m}$ and arranged by the regular triangle. The laying of the steel-plastic geogrids should be continuous, so that there is no distortion, wrinkle, overlap, or other phenomena, to ensure that the base level and dense.

(3) Construction Joints. Settlement joints, of which width is $1 \mathrm{~cm}$, should be provided along the cross section of lightweight concrete, faceplate, and foundation between casting sections. The joints should be filled with the asphalt boards.

(4) Protection Panels. After the filling of lightweight concrete is completed, precast cement panels are used along the sides to serve as protection measures and reinforced with angle steel, as shown in Figure 7. Transverse panels are arranged between the lightweight concrete and the abutment and the connecting end of the filling concrete. Additionally, a layer of polyethylene foam is arranged between the panel and the abutment.

\subsection{Construction Quality Control}

2.2.1. Control of Fluidity, Wet Density, and Compressive Strength. Before formal pouring, it is necessary to select a section for a field test to determine the various control parameters, to guide the subsequent construction. The construction quality management of lightweight concrete usually requires testing whether the compressive strength can reach the designed strength. However, the strength test results can only be obtained after curing for 28 days. As a result, the method of controlling wet density and fluidity is often used in the construction process. But it is still necessary to verify the final compressive strength.

Wet density and fluidity are measured simultaneously during the casting process. And a standard test block of $100 \mathrm{~mm} \times 100 \mathrm{~mm} \times 100 \mathrm{~mm}$ is adopted to measure the compressive strength after the appropriate curing time, which meets the requirement of ASTM C567 [31].

The test results of fluidity, wet density, and compressive strength are shown in Table 3 and Figure 8. It can be seen that the wet density of the lightweight concrete of IMR and EMR is less than $7 \mathrm{kN} / \mathrm{m}^{3}$, and the wet density of IMR is smaller than that of EMR. At the same time, both flow values meet the requirements of $180( \pm 20) \mathrm{mm}$. As can be seen from Figure 8, the strengths of the two ratios at seven days are $0.62 \mathrm{MPa}$ and $0.85 \mathrm{MPa}$, respectively, both of which are greater than 0.5 times of the designed strength, and the compressive strengths at 28 days are both greater than the designed strength. After 60 days, the strength of IMR is still lower than that of EMR, and at the age of 90 days, it exceeds that of EMR. On the whole, the compressive strength of all ages measured in the room is slightly smaller than that measured in the field, but has higher long-term strength and meets the strength requirements, indicating that the optimal mixture ratio with fly ash in the room can also meet the requirements of embankment filling. Because fly ash is cheaper than cement, and it is conducive to reducing environmental pollution and energy waste, IMR is more economical and more environmentally friendly than EMR.

\subsubsection{Control of Single-Layer Casting Thickness}

(1) Vertical Delamination Rate (VDR). To ensure the uniformity and reduce the heat of hydration, the layered and block pouring method should be adopted for lightweight 


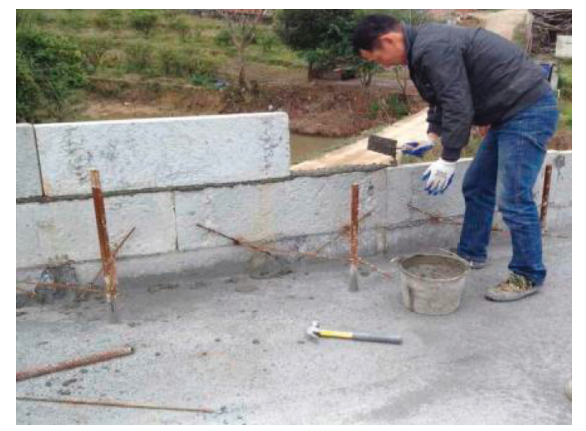

(a)

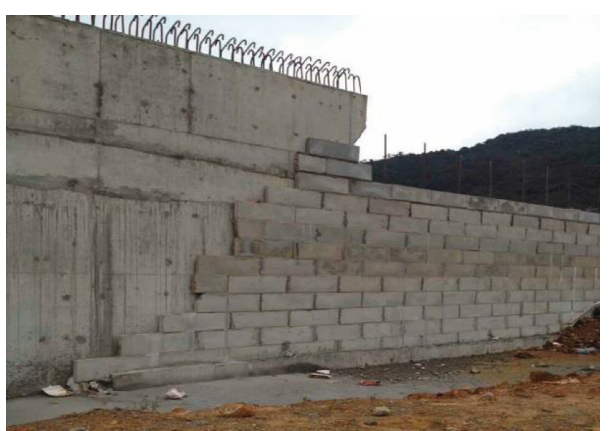

(b)

Figure 7: (a, b) Cement panel protection.

TABLE 3: Test results of fluidity, wet density, and compressive strength.

\begin{tabular}{lccccccc}
\hline $\begin{array}{l}\text { Mixture } \\
\text { ratio }\end{array}$ & $\begin{array}{c}\text { Wet density } \\
\left(\mathrm{kN} / \mathrm{m}^{3}\right)\end{array}$ & $\begin{array}{c}\text { Flow value } \\
(\mathrm{mm})\end{array}$ & \multicolumn{5}{c}{$\begin{array}{c}\text { Unconfined compressive } \\
\text { strength (MPa) }\end{array}$} \\
\hline IMR & 6.78 & 192 & 0.62 & 0.87 & 1.02 & 1.18 & 1.36 \\
EMR & 6.94 & 168 & 0.85 & 1.00 & 1.10 & 1.21 & 1.26 \\
\hline
\end{tabular}

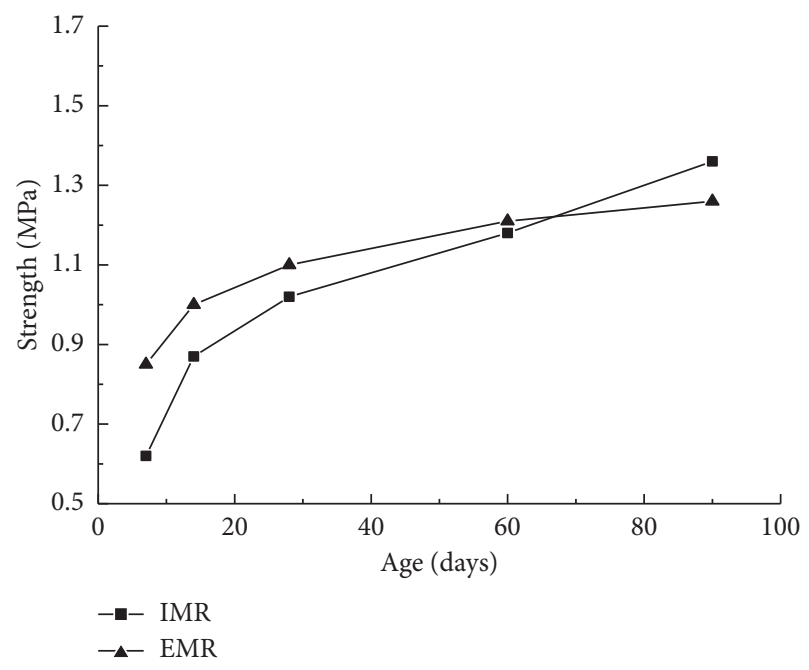

Figure 8: Strength changing with time.

concrete, and the thickness of the single layer should be strictly controlled. However, there are few studies on the single-layer thickness of lightweight concrete at home and abroad, and there is no clear control method. It is often decided by subjective experience in a practical engineering project. According to the Chinese Standard of Technical Specification for LCC Filling Engineering [32], the minimum compressive strength value of LCC test blocks should be $85 \%$ of the standard value, that is to say, the strength deviation of LCC test blocks should not be greater than 15\% of the standard strength value. And the test method and strength index meet the requirements of ASTM C31 [33] and ASTM C495 [34]. Therefore, VDR of lightweight concrete is defined as

$$
\delta=\frac{q_{\mathrm{u}, \mathrm{b}}-q_{\mathrm{u}, \mathrm{t}}}{q_{\mathrm{u}, \mathrm{b}}},
$$

where $q_{\mathrm{u}, \mathrm{b}}$ and $q_{\mathrm{u}, \mathrm{t}}(\mathrm{MPa})$ are the compressive strengths of bottom and top of lightweight concrete in a certain depth range. $\delta(\%), \mathrm{VDR}$, can be used as a discriminant index for the pouring thickness of a single layer. And it can be considered that the uniformity is better when the rate is less than $15 \%$.

(2) Vertical Delamination Test and Result Analysis. Six PVC circular pipes with a diameter of $100 \mathrm{~mm}$ and a height of $700 \mathrm{~mm}$ are placed vertically on the flat site, 3 of which are used for pouring slurry of IMR and the others are used for pouring slurry of EMR. The bottom of the PVC pipe, which will be filled with cement slurry, is sealed. Tap the outer side of the PVC pipe to make the surface of the slurry flush with the top end of the pipe. Then cover the top end with plastic film for curing. After curing for 28 days, cut the PVC pipe into seven segments, with each segment height of $100 \mathrm{~mm}$, as shown in Figure 9. Take out the lightweight concrete cylindrical samples and test their strengths, as shown in Figure 10. During the cutting process, the flatness of the cutting section should be ensured. The cutting face should be patched with epoxy cement, and the thickness of the patched layer should be controlled to be less than $2 \mathrm{~mm}$. If the sample has cracks or poor flatness of cutting section, it is invalid.

The results of VDR and the strength of the samples for 28 days are shown in Table 4 and Figure 11. It can be seen from Figure 11 that VDRs of samples of IMR and EMR are basically the same along the depth, and both increase with the increase of depth, indicating that the greater the thickness of the single layer is, the more uneven the concrete will be. The curves also change from steep to slow, indicating that with the increase of depth, the growth of VDR gradually decreases, and the delamination tends to be stable. When the depth is less than $600 \mathrm{~mm}$, the delamination degree of IMR sample is more severe than that of EMR sample. When the depth is greater than $600 \mathrm{~mm}$, the delamination degree of both is almost the same. It can also be seen from the test results that when the depth is greater than $500 \mathrm{~mm}$, VDR is greater than $15 \%$. Therefore, it is suggested that the thickness of the single layer should be controlled within the range of $500 \mathrm{~mm}$. 


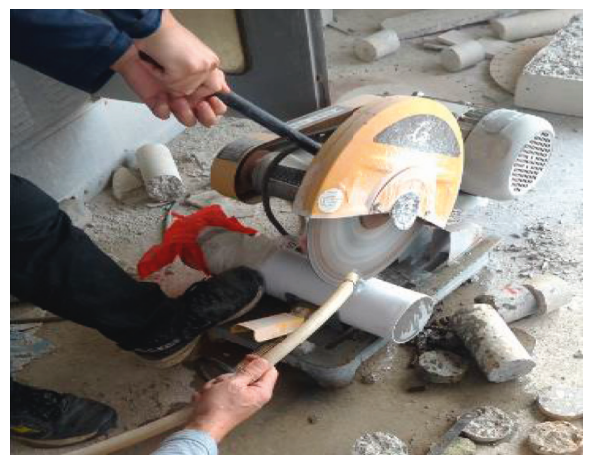

Figure 9: Cutting the sample.

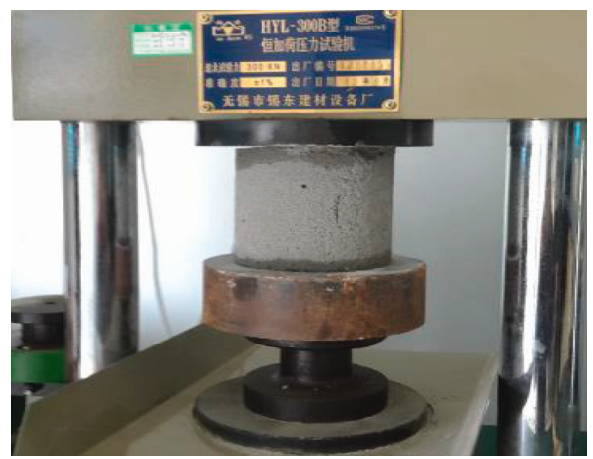

FIGURE 10: Testing the compressive strength.

TABLE 4: Results of VDR

\begin{tabular}{lcccc}
\hline \multirow{2}{*}{ Depth (mm) } & IMR & \multicolumn{2}{c}{ EMR } \\
& Strength $(\mathrm{MPa})$ & $\delta(\%)$ & Strength $(\mathrm{MPa})$ & $\delta(\%)$ \\
\hline 100 & 1.02 & 0 & 1.28 & 0 \\
200 & 1.09 & 6.42 & 1.36 & 5.88 \\
300 & 1.14 & 10.53 & 1.41 & 9.22 \\
400 & 1.18 & 13.56 & 1.46 & 12.33 \\
500 & 1.2 & 15.00 & 1.49 & 14.09 \\
600 & 1.21 & 15.70 & 1.52 & 15.79 \\
700 & 1.22 & 16.39 & 1.53 & 16.34 \\
\hline
\end{tabular}

To sum up, there are a large number of air bubbles in lightweight concrete. During pouring, due to the influence of gravity, the air bubbles will float up, compress, and dissolve, leading to a large volume weight and a large strength in the lower part, while a small volume weight and a small strength in the upper part, resulting in the initial damage of lightweight concrete. The uniformity is affected by the thickness of a single layer. The greater the thickness of the single layer is, the more uneven the concrete will be, and the more serious the initial damage will be. Therefore, the thickness of a single layer cannot be too thick and should be controlled within a certain range. According to the experimental results, it is considered that the uniformity is better when the thickness of the single layer is within the range of $500 \mathrm{~mm}$.

(3) Strength Test along the Depth. In addition, a patented test method has also been designed to determine the strength characteristics of LCC at different depths along the embankment. The process is based on a designed test device as shown in Figure 12, including worm 1, gearbox 2, panel 3, pressure sensor 4 , leg 5 , sample tube 6 , drill 7, pedestal 8 , electromotor 9, and displacement sensor 10, to conduct penetration test and determine the bearing capacity $p_{i}$ and maximum bearing capacity $p_{\max }$ at different depths. Through force analysis of a specially designed annular frictionless drill, the relationship between bearing capacity and compressive strength $f_{\mathrm{c}}$ can be established. This method can optimize the thickness and uniformity of a singer layer and improve the quality of embankment filling. The specific test method is shown below.

As is shown in Figure 13, $\overline{A B}$ is the outer diameter difference between drill 7 and sample tube 6 , and the length is $20 \mathrm{~mm} . \overline{B C}$ is the wall thickness of the sample tube 6 , and the thickness is $10 \mathrm{~mm} . \overline{C D}$ is the inner diameter shrinkage value of the tail of the drill, with a size of $10 \mathrm{~mm} \cdot \overline{O_{1} D_{1}}$ is the radius of the end of the drill, with a size of $r . \overline{O O_{1}}$ is the length of the drill with a size of $h . \overline{A D_{1}}$ is the length of the conic bus of the drill and its size is $L . P_{i}$ is the penetration force. $\angle A D_{1} D$ is the half apex angle of the cone, and the size is $\theta$. follows:

The surface area of the cone with $\overline{A D_{1}}$ as the busbar is as

$$
S=\pi \overline{A O A O_{2}}-\pi \overline{D_{1} O_{1} D_{1} O_{2}}=\frac{\pi}{\sin \theta}\left(R^{2}-r^{2}\right) .
$$

According to the static equilibrium conditions, the vertical force acting on the cone surface of the drill is $P_{i}$, so the normal force is

$$
F_{i}=P_{i} \sin \theta
$$

The normal stress of the drill somewhere along the embankment depth is as follows:

$$
\sigma_{i}=\frac{F_{i}}{S}=\frac{P_{i} \sin ^{2} \theta}{\pi\left(R^{2}-r^{2}\right)} .
$$

According to the characteristics of homogeneity and isotropy, the compressive strength of LCC is as follows:

$$
\begin{aligned}
& f_{\mathrm{c}}=\sigma_{i}=\frac{P_{i} \sin ^{2} \theta}{\pi\left(R^{2}-r^{2}\right)}, \\
& f_{\mathrm{cx}}=\sigma_{i} \sin \theta=\frac{P_{i} \sin ^{3} \theta}{\pi\left(R^{2}-r^{2}\right)}, \\
& f_{\mathrm{cy}}=\sigma_{i} \cos \theta=\frac{P_{i} \sin ^{2} \theta \cos \theta}{\pi\left(R^{2}-r^{2}\right)} .
\end{aligned}
$$

To ensure the reliability of the data, unconfined compressive strength tests can be conducted on concrete samples obtained from sample tube 6 in the laboratory, so indoor compressive strength $f_{\text {cu }}$ can be obtained. The correction coefficient can be calculated compared with field data. Also, $P_{i}$ at different depths can be substituted into formulae (5)-(7) to calculate the compressive strength and vertical and horizontal components, to draw the strength test curve along the embankment depth during the construction period of LCC. 


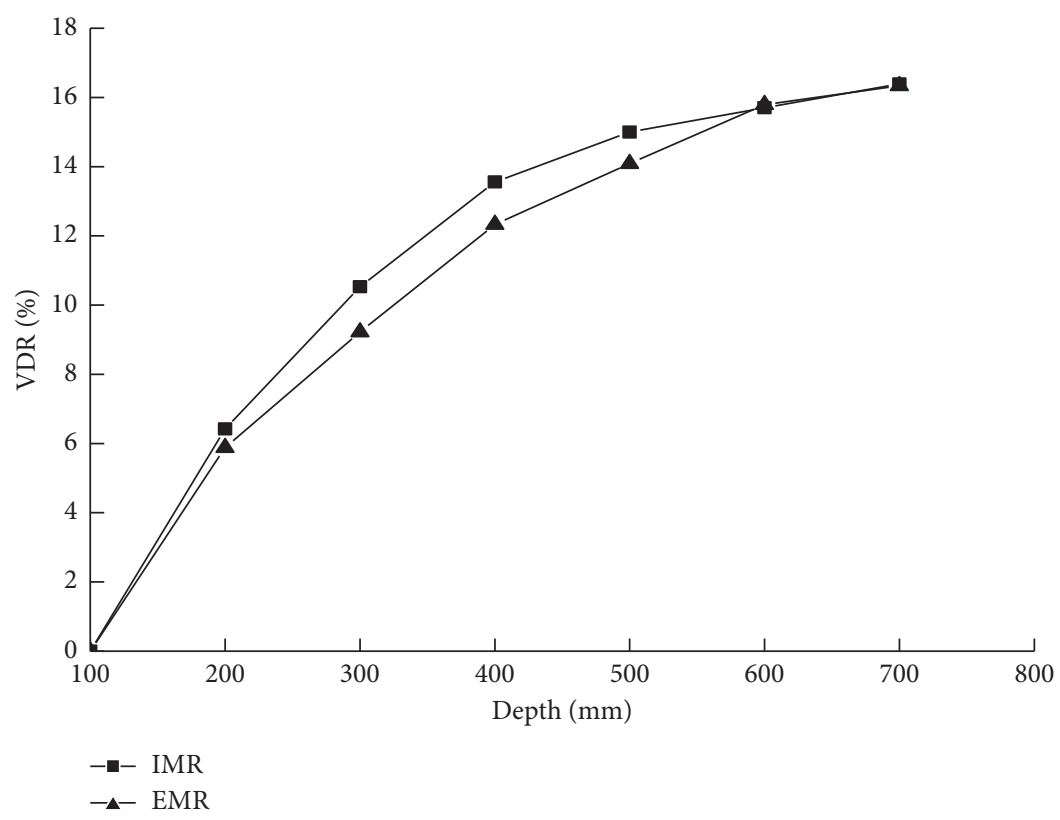

FIgURE 11: VDR varying along the depth.

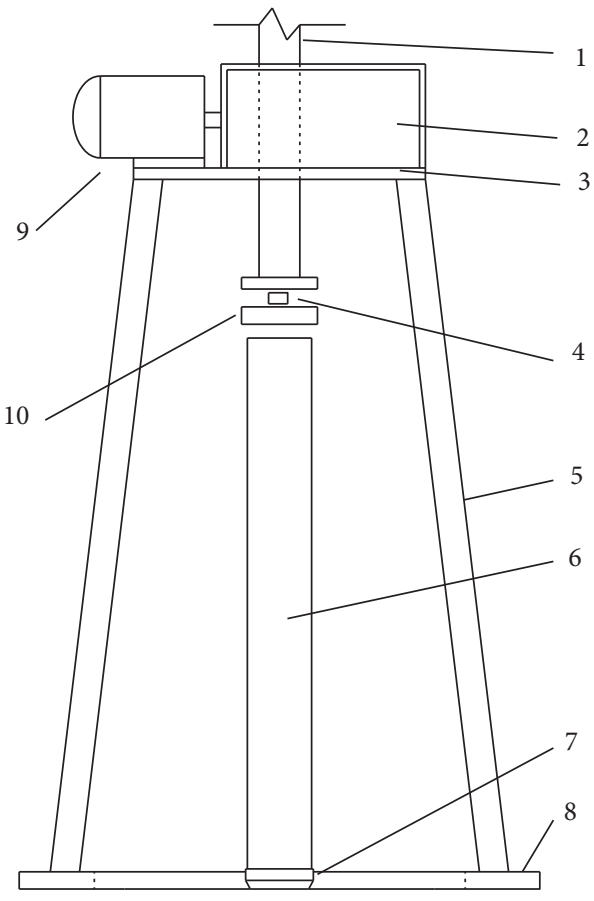

Figure 12: Test device.

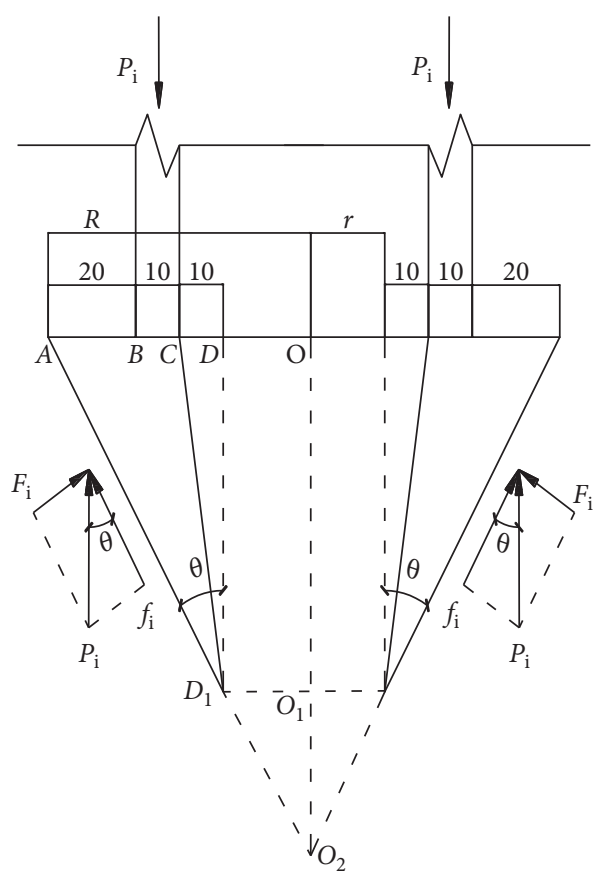

Figure 13: Annular frictionless drill.
2.2.3. Control of the Interval Time between Layers. The construction method of layered pouring is adopted for lightweight concrete. When pouring the upper layer, the construction personnel should stand on the filling body of the lower layer, as shown in Figure 14. Therefore, it is necessary to control the interval time between layers to ensure that the poured body is strong enough to support the next step of construction and ensure the safety of construction.
(1) Experiment Design. Suppose a construction worker weighs $85 \mathrm{~kg}$, and one foot is $25 \mathrm{~cm}$ long and $10 \mathrm{~cm}$ wide. When a person walks, he lands on the heel of one foot, so the maximum pressure on the ground while walking is as follows:

$$
P=\frac{85 \times 10}{0.5 \times 25 \times 10 \times 10^{-4}} \times 10^{-3}=68 \mathrm{kPa} .
$$

Also, pressure is also generated by the weight of support for securing the pumping line and the pipeline. According to 


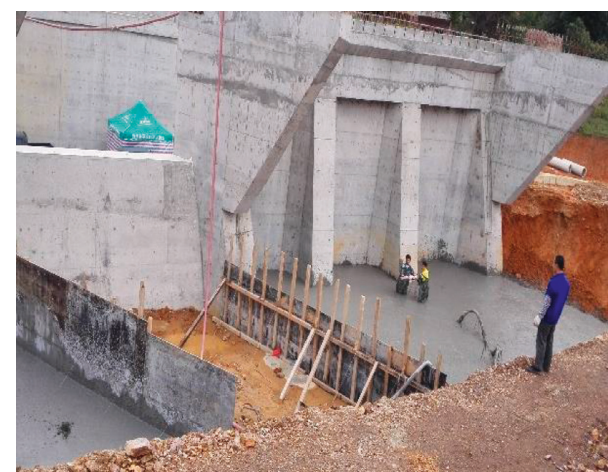

FIgURE 14: Schematic diagram of pouring.

estimation, the weight is $30 \mathrm{~kg}$, and the area is about $3.125 \times 10^{-3} \mathrm{~m}^{2}$. Therefore,

$$
P^{\prime}=\frac{30 \times 10}{3.125 \times 10^{-3}} \times 10^{-3}=96 \mathrm{kPa} .
$$

Considering that walking people and the flow and pouring of slurry will have an impact on the ground, for variable load, the final result needs to be converted, and the safety coefficient is 1.2 . Thus, when the upper layer is to be poured, the strength of the filled body of the lower layer should be $(68+96) * 1.2=196.80 \mathrm{kPa}$. So take it as $200 \mathrm{kPa}$.

The cement starts to harden after the final setting, and its strength increases slowly, so the surface strength should be measured after the final setting. The surface strength tester is used to measure the surface strength of the lightweight concrete embankment.

(2) Surface Strength Tester. The patented tester, of which the design drawings are shown in Figures 15-17, is used for this test, with loading system, strength transfer system, and data acquisition system. According to the time after pouring, it is divided into three stages: the first stage is $4-8$ hours, then test with thin-film spherical column feet, the second stage is $8-24$ hours with metal spherical column feet, and the third stage is 24 hours later with conical column feet. Take the second stage as an example.

(i) After the loading system instrument is assembled, the metal spherical column feet are installed and placed on the lightweight concrete. Long leveling bubbles and leveling screws are used to level and eliminate assembly errors.

(ii) The method of multistage loading is accepted with the same static time each time. After the last loading to the final loading weight $m$, the loading is stopped and static. Record the sag values $\Delta h_{1}, \Delta h_{2}, \Delta h_{3}$ on the three sides, take the sum of the sag values, and calculate the average value.

(iii) The calculation diagram is shown in Figure 18. Assuming that the radius of the metal spherical column foot is $R$, the average sag value is denoted as $h$, and the radius of the projective plane is set as $r$; the projective area of the contact area of the metal

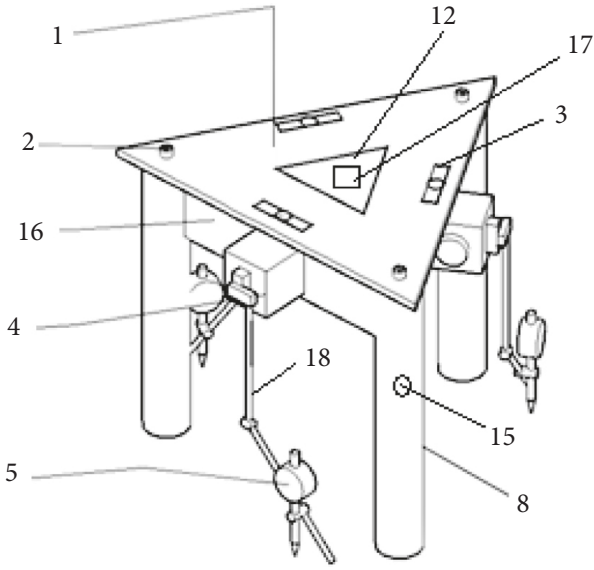

FIgURE 15: Structural representation.

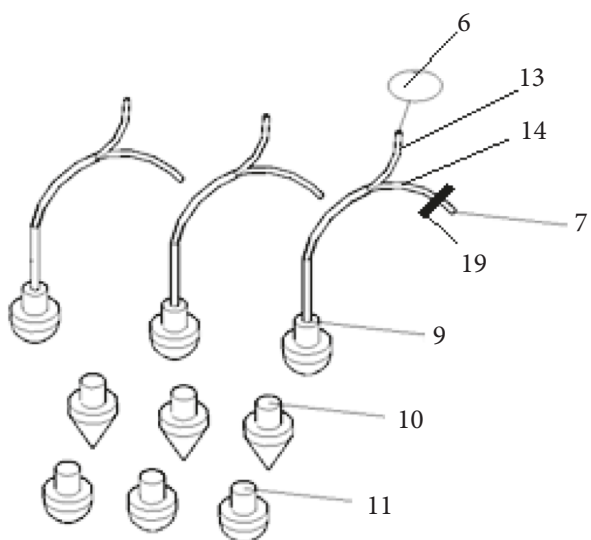

Figure 16: Schematic diagram of column feet.
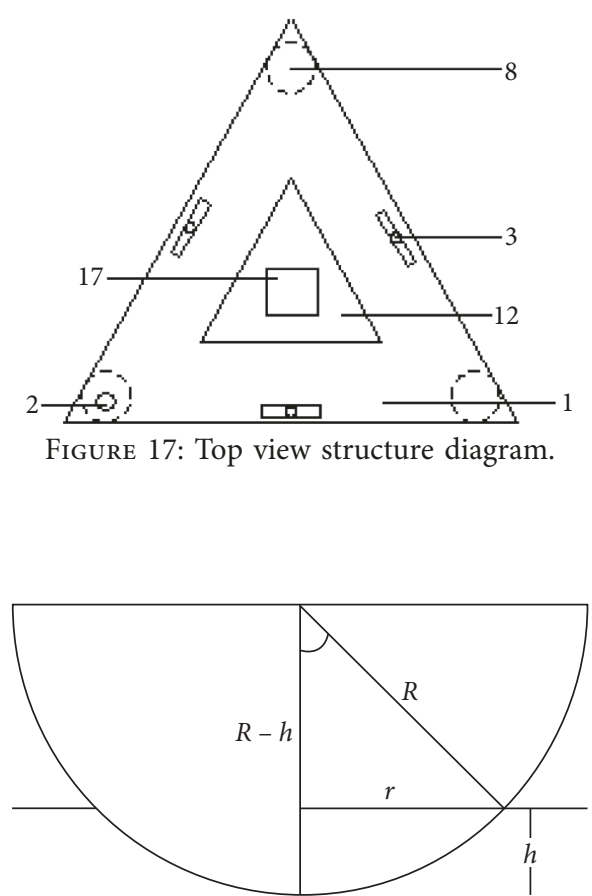

Figure 18: Calculation diagram. 


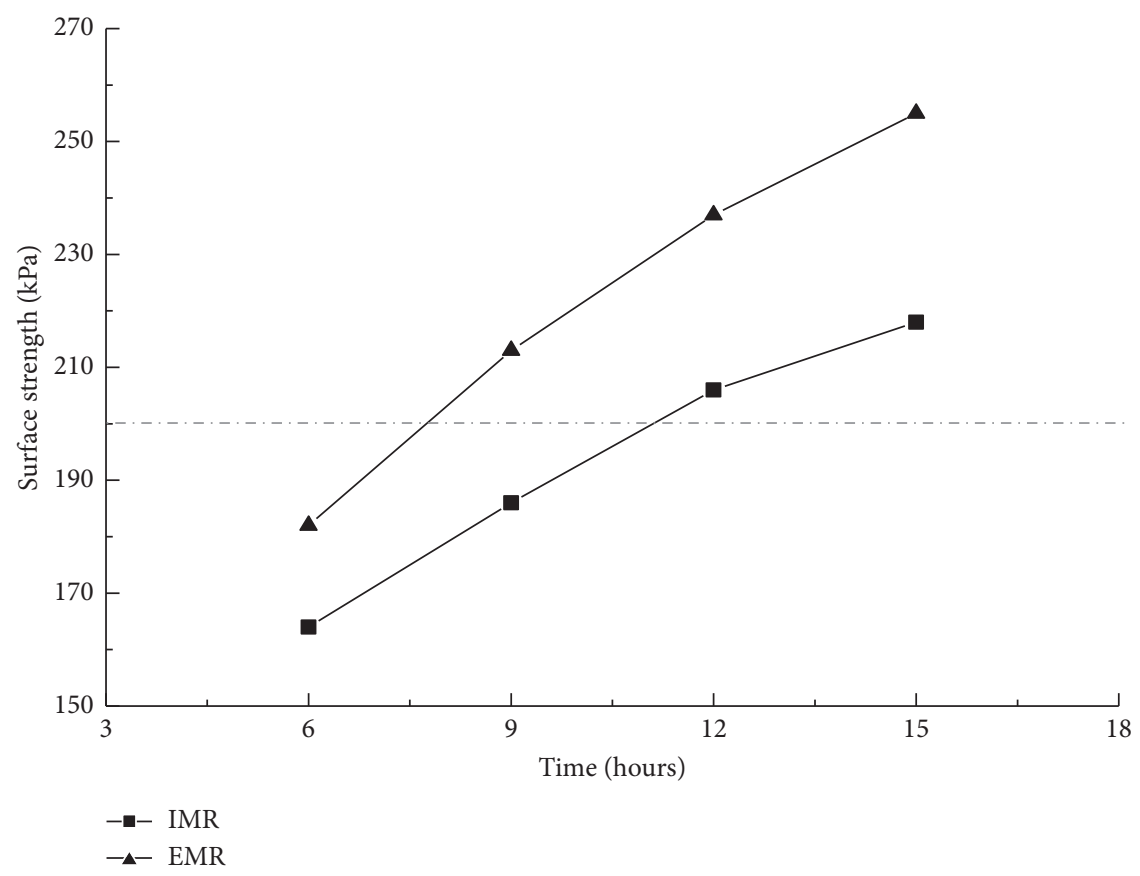

FIgURE 19: Surface strength test results at high temperature.

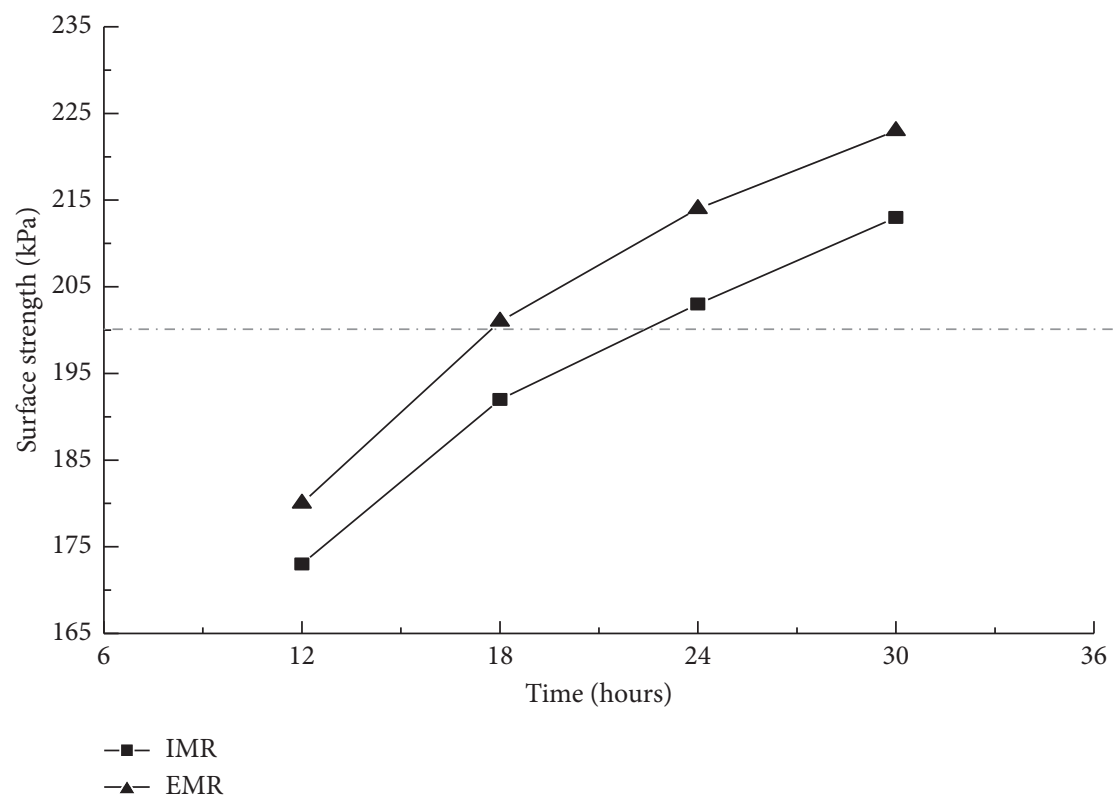

Figure 20: Surface strength test results at a low temperature.

spherical column foot on the horizontal plane can be calculated as follows:

$$
\begin{aligned}
(R-h)^{2}+r^{2} & =R^{2}, \\
r & =\sqrt{R^{2}-(R-h)^{2}}, \\
A & =\pi r^{2} .
\end{aligned}
$$

Then the surface strength is derived from the pressure formula: $p=m g /\left[\pi\left(R^{2}-(R-h)^{2}\right)\right]$.
As shown in Figures 15-17, 1 is equilateral triangle panel, 2 is leveling screw, 3 is long leveling bubbles, 4 is magnetic stand, 5 is displacement meter, 6 is barometer, 7 is pressurizing mouth, 8 is support, 9 is thin-film spherical column feet, 10 is conical column feet, 11 is metal spherical column feet, 12 is groove, 13 is the first branch, 14 is the second branch, 15 is through-hole, 16 is side plate, 17 is load weight, 18 is the connecting rod, and 19 is the sealing clamp.

(3) Test Results. The project is constructed in winter. The winter temperature in Guangdong is not stable, and the 
average maximum temperature is close to $30^{\circ} \mathrm{C}$, while the lowest is close to $5^{\circ} \mathrm{C}$. According to the Chinese Standard of Technical Specification for LCC Filling Engineering [32], it is suggested to avoid pouring lightweight concrete at high temperature, while in winter, it is suggested to take heat preservation and antifreezing measures for the pouring equipment, pumping pipes, foaming agent, and pouring area. Therefore, two sections are selected for surface strength test and test results are shown in Figures 19 and 20. The results indicate that, at low temperature, the interval time between layers is greater than that at high temperature, and the interval time of IMR is greater than that of EMR. At high temperature, the interval time of EMR is at least $9 \mathrm{~h}$ after final setting, and that of IMR is at least $12 \mathrm{~h}$. At low temperature, the interval time is $18 \mathrm{~h}$ and $24 \mathrm{~h}$, respectively. Therefore, during the construction, the weather conditions should be paid attention to and recorded in detail, and the interval time between layers should be controlled according to the actual temperature.

\section{Conclusions}

In this paper, the application effects of IMR and EMR are studied by a field test. Combined with the practice, the construction technology of lightweight concrete is also put forward. The main conclusions are as follows:

(a) The improved preparation methods of LCCF in laboratory and in actual construction are put forward in the paper. And the construction technology control tests and evaluation of the lightweight concrete are studied to guide the construction of similar projects.

(b) Through field measurement of fluidity, wet density, and strength of lightweight concrete of IMR and EMR, it is found out that the strength of lightweight concrete of IMR at 28 days is lower than that of EMR, but it can also meet the requirement of strength that should be over $1 \mathrm{MPa}$, and the wet density is slightly lower, which verified the feasibility of the mixture ratio of LCCF.

(c) Through the field vertical delamination test by use of a patented tester which determines the strength characteristics of LCC at different depths, it is concluded that VDRs of IMR and EMR have roughly the same change rule along the depth, both increasing with the increase of depth, and the increased range gradually decreases and tends to be stable. According to the test results, it is suggested that the thickness of the single layer should be controlled within $500 \mathrm{~mm}$.

(d) According to the field surface strength test by use of a patented strength tester, it is concluded that, at low temperature, the interval time between layers is greater than that at high temperature, and the interval time of IMR is greater than that of EMR. At high temperature, the interval time of EMR is at least
$9 \mathrm{~h}$ after final setting, and that of IMR is at least $12 \mathrm{~h}$. At low temperature, the interval time is $18 \mathrm{~h}$ and $24 \mathrm{~h}$, respectively.

\section{Data Availability}

No data were used to support this study.

\section{Conflicts of Interest}

The authors declare that they have no conflicts of interest.

\section{Acknowledgments}

Support for this research was provided in part by National Natural Science Foundation of China (Grant No. 51609071), the Fundamental Research Funds for the Central Universities (Grant Nos. 2018B13714 and 2019B44114), and China Scholarship Council (Grant No. 201806715014).

\section{References}

[1] E. Namsone, G. Š msonec, and A. Korjakins, "Durability properties of high performance foamed concrete," Procedia Engineering, vol. 172, pp. 760-767, 2017.

[2] S.-C. Ng, K.-S. Low, and N.-H. Tioh, "Potential use of clayey soil in aerated lightweight concrete," KSCE Journal of Civil Engineering, vol. 16, no. 5, pp. 809-815, 2012.

[3] G. C. Wang, L. Sha, and F. L. Jin, "Study on the strength properties and failure mode of recycled sludge lightweight soil," Applied Mechanics and Materials, vol. 275-277, pp. 1281-1284, 2013.

[4] X. Liu, K. Sheng, and H. Shan, "Discussion of "revised soil classification system for coarse-fine mixtures" by Junghee Park and J. Carlos Santamarina," Journal of Geotechnical and Geoenvironmental Engineering, vol. 144, no. 8, article 07018017, 2018.

[5] C. Liu, X. Wei, Z. Lu, H. Wu, Y. Yang, and L. Chen, "Studies on passive flexible protection to resist landslides caused by the May 12, 2008, Wenchuan earthquake," The Structural Design of Tall and Special Buildings, vol. 26, no. 11, p. e1372, 2017.

[6] Y. Watabe, M. Tanaka, H. Saegusa et al., "Long-term properties of airfoam-treated lightweight concrete made from dredged clay," Journal of Astm International, vol. 6, no. 4, 2009.

[7] Z. L. Li and K. F. Zhang, "Application and research on new technology of foam lightweight soil in treatment of soft soil foundation of railway engineering," Applied Mechanics and Materials, vol. 204-208, pp. 1622-1625, 2012.

[8] D.-W. Park and H. V. Vo, "Evaluation of air-foam stabilized soil of dredged soil waste as a pavement subgrade layer," Ksce Journal of Civil Engineering, vol. 19, no. 7, pp. 2091-2097, 2015.

[9] N. Makul and G. Sua-Iam, "Characteristics and utilization of sugarcane filter cake waste in the production of lightweight foamed concrete," Journal of Cleaner Production, vol. 126, pp. 118-133, 2016.

[10] C. Zhou, "Mechanical properties the cast in situ foamed lightweight concrete," Key Engineering Materials, vol. 703, 2016.

[11] D. Shen, X. Liu, Q. Li, L. Sun, and W. Wang, "Early-age behavior and cracking resistance of high-strength concrete 
reinforced with Dramix 3D steel fiber," Construction and Building Materials, vol. 196, pp. 307-316, 2019.

[12] X. Liu, L. I. Zhilong, L. Gan et al., "Durability assessment of foamed mixture lightweight concrete based on analytic hierarchy process and fuzzy comprehensive evaluation (AHPFCE)," Journal of Hohai University, vol. 45, no. 4, pp. 332-339, 2017.

[13] S. Horiuchi, M. Kawaguchi, and K. Yasuhara, "Effective use of fly ash slurry as fill material," Journal of hazardous materials, vol. 76, no. 2-3, pp. 301-337, 2000.

[14] M. Ahmaruzzaman, "A review on the utilization of fly ash," Progress in Energy and Combustion Science, vol. 36, no. 3, pp. 327-363, 2010.

[15] B. González-Corrochano, J. Alonso-Azcárate, and M. Rodas, "Effect of thermal treatment on the retention of chemical elements in the structure of lightweight aggregates manufactured from contaminated mine soil and fly ash," Construction and Building Materials, vol. 35, pp. 497-507, 2012.

[16] H. L. Li, C. Z. Jin, C. F. Yang, and H. N. Gao, "Research on the stress-strain law of abutment approach embankment filled with liquid fly ash," Advanced Materials Research, vol. 1065-1069, pp. 536-539, 2014.

[17] Z. T. Yao, X. S. Ji, P. K. Sarker et al., "A comprehensive review on the applications of coal fly ash," Earth-Science Reviews, vol. 141, pp. 105-121, 2015.

[18] F. Santos, L. Li, Y. Li et al., "Geotechnical properties of fly-ash and soil mixtures for use in highway embankments," in Proceedings of the World of Coal Ash (WOCA) Conference, Denver, CO, USA, May 2011.

[19] N. M. Ibrahim, R. C. Amat, S. Salehuddin et al., "Properties of lightweight concrete composites with mixture of fly-ash and concrete sludge aggregate," Key Engineering Materials, vol. 594-595, pp. 482-486, 2014.

[20] N. M. Ibrahim, K. N. Ismail, A. R. Abdul Razak et al., "Utilisation of recycled concrete sludge aggregate and fly-ash in the production of lightweight foamed concrete for environmental sustainability," International Proceedings of Chemical Biological and Environmenta, vol. 68, pp. 29-33, 2014.

[21] Y.-S. Luo, J. Li, and A. Chan, "Study on the engineering property of mixed-soil fly ash," in Advances in Environmental Geotechnics, pp. 721-727, 2010.

[22] Y. H. Fang, Q. Wen, and P. Dai, "Investigation on the property and air void structure of foamed cement-fly ash-steel slag concrete," Advanced Materials Research, vol. 150-151, pp. 1457-1461, 2010.

[23] P. Chindaprasirt and U. Rattanasak, "Shrinkage behavior of structural foam lightweight concrete containing glycol compounds and fly ash," Materials and Design, vol. 32, no. 2, pp. 723-727, 2011.

[24] P. Shafigh, U. Johnson Alengaram, H. B. Mahmud, and M. Z. Jumaat, "Engineering properties of oil palm shell lightweight concrete containing fly ash," Materials and Design, vol. 49, no. 1, pp. 613-621, 2013.

[25] N. M. Ibrahim, R. C. Amat, S. Salehuddin, N. L. Rahim, A. R. A. Razak, and W. H. Ooi, "Properties of lightweight concrete composites with mixture of fly ash and concrete sludge aggregate," Key Engineering Materials, vol. 594-595, pp. 482-486, 2013.

[26] X. Liu, L. Q. Gan, K. Sheng et al., "Experimental study on service life of foamed mixture lightweight concrete based on method of accelerated stress tests," Yantu Gongcheng Xuebao/ Chinese Journal of Geotechnical Engineering, vol. 39, no. 10, pp. 1793-1799, 2017.
[27] X. Liu, K. Sheng, Z.-L. Li, L.-Q. Gan, H. Shan, and B.-N. Hong, "Experimental research on foamed mixture lightweight concrete mixed with fly-ash and quicklime as backfill material behind abutments of expressway Bridge," Advances in Materials Science and Engineering, vol. 2017, Article ID 5767103, 11 pages, 2017.

[28] X. Bian, Y. J. Cui, and X. Z. Li, "Voids effect on the swelling behaviour of compacted bentonite," Géotechnique, vol. 69, no. 7, pp. 593-605, 2018.

[29] ASTM C311/C311M-18, Standard Test Methods for Sampling and Testing Fly Ash or Natural Pozzolans for Use in PortlandCement Concrete, ASTM International, West Conshohocken, PA, USA, 2018, http://www.astm.org.

[30] ASTM C618-19, Standard Specification for Coal Fly Ash and Raw or Calcined Natural Pozzolan for Use in Concrete, ASTM International, West Conshohocken, PA, USA, 2019, http:// www.astm.org.

[31] ASTM C567/C567M-14, Standard Test Method for Determining Density of Structural Lightweight Concrete, ASTM International, West Conshohocken, PA, USA, 2014, http:// www.astm.org.

[32] GuangDong GuanSheng Civil Engineering Technology Co Ltd, "Technical specification for foamed mixture lightweight soil filling engineering," Tech. Rep. CJJ/T 177-2012, China Architecture \& Building Press, Beijing, China, 2012.

[33] ASTM C31/C31M-19, Standard Practice for Making and Curing Concrete Test Specimens in the Field, ASTM International, West Conshohocken, PA, USA, 2019, http://www. astm.org.

[34] ASTM C495/C495M-12, Standard Test Method for Compressive Strength of Lightweight Insulating Concrete, ASTM International, West Conshohocken, PA, USA, 2012, http:// www.astm.org. 


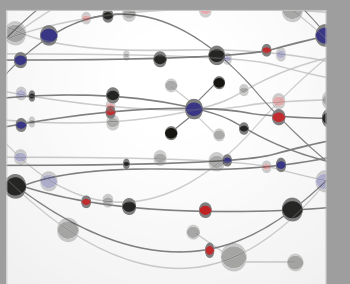

The Scientific World Journal
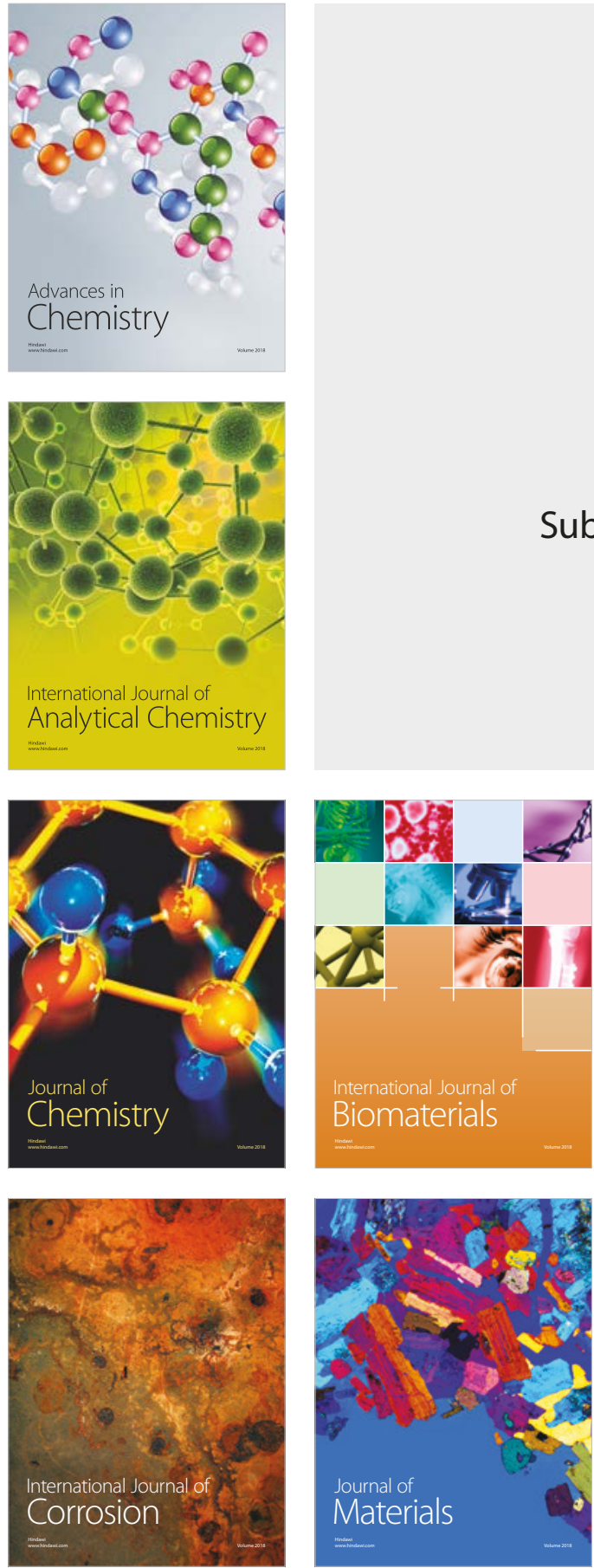

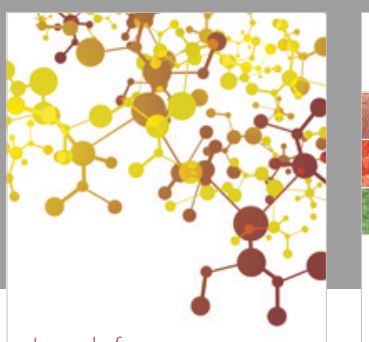

Journal of

Applied Chemistry
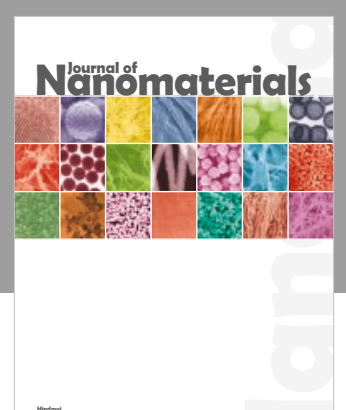

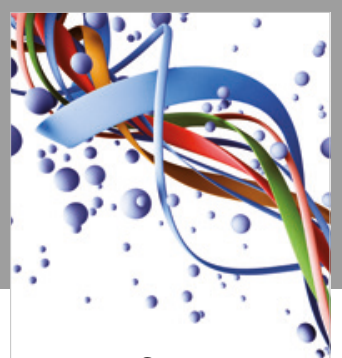

Scientifica

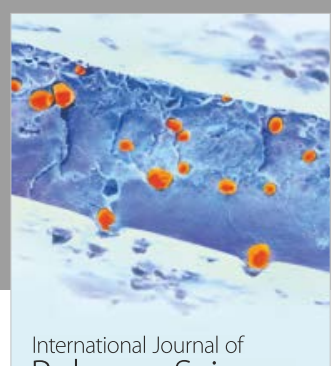

Polymer Science

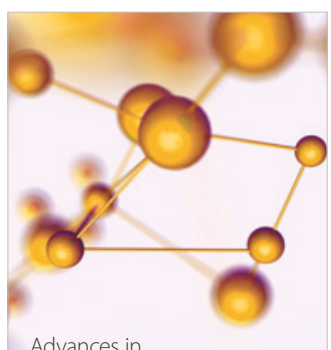

Physical Chemistry
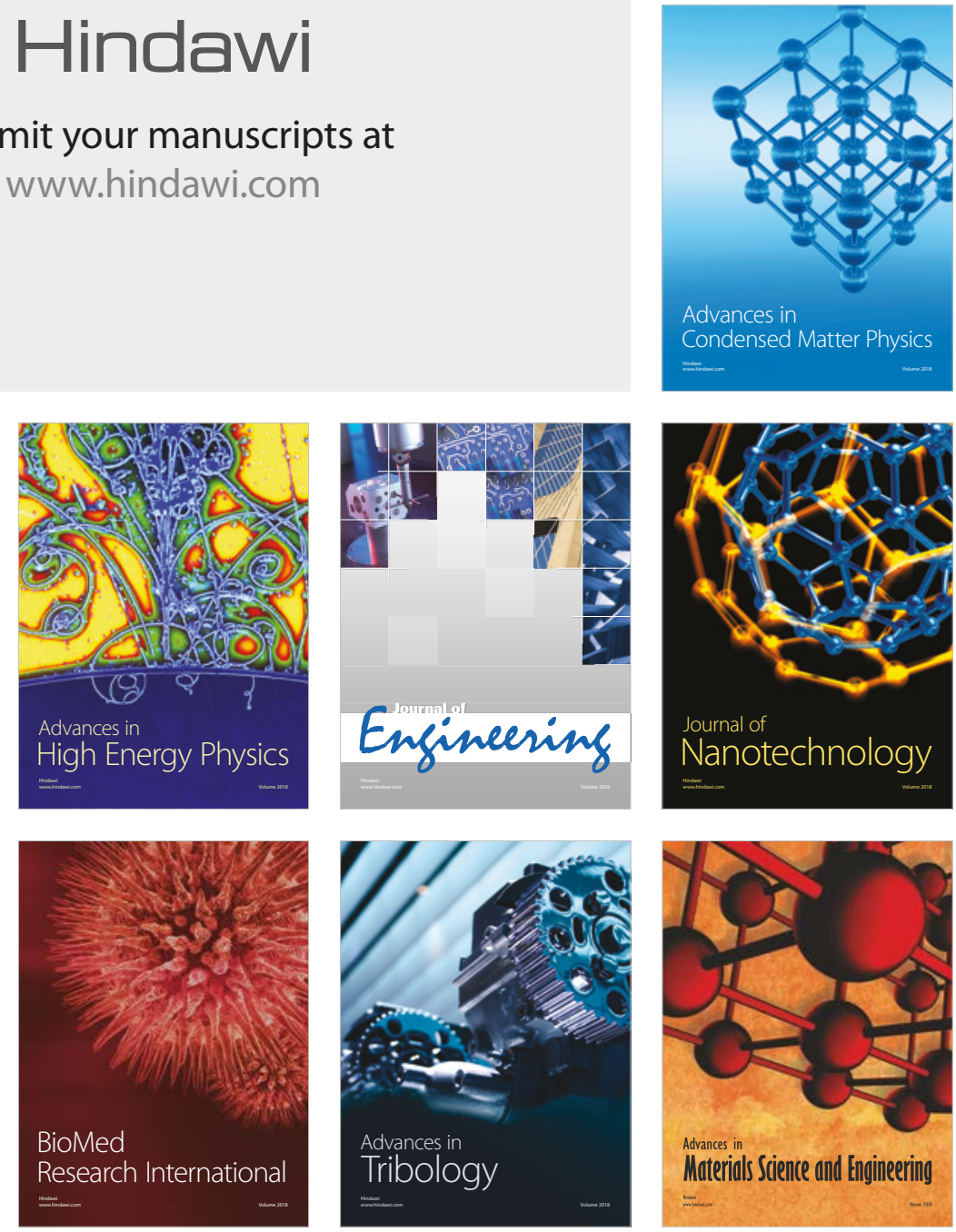